\title{
Autonomic Function and QT Interval During Night-Time Sleep in Infant Long QT Syndrome
}

\author{
Masao Yoshinaga, MD, PhD; Yu Kucho, MD; Hiroya Ushinohama, MD, PhD; \\ Yuichi Ishikawa, MD, PhD; Seiko Ohno, MD, PhD; Hiromitsu Ogata, PhD
}

\begin{abstract}
Background: Sudden infant death syndrome mainly occurs during night-time sleep. Approximately $10 \%$ of cases are thought to involve infants with long QT syndrome (LQTS). Autonomic function and QT interval in night-time sleep in early infancy in LQTS infants, however, remain controversial.

Methods and Results: Holter electrocardiography was performed in 11 LQTS infants before medication in early infancy, and in 11 age-matched control infants. Control infants were re-evaluated in late infancy. The power spectral density was calculated and parasympathetic activity and sympathovagal balance were obtained. Electrocardiograms of a representative hour during night-time sleep, daytime sleep, and daytime activity, were chosen and QT/RR intervals were manually measured. LQTS infants had significantly lower parasympathetic activity and higher sympathovagal balance during night-time sleep than control infants in early infancy. These autonomic conditions in early infancy were significantly depressed compared with late infancy. Corrected QT interval (QTc) during night-time sleep $(490 \pm 20 \mathrm{~ms})$ was significantly longer than that in daytime sleep $(477 \pm 21 \mathrm{~ms}, \mathrm{P}=0.04)$ or daytime activity $(458 \pm 18 \mathrm{~ms}$, $\mathrm{P}=0.003$ ) in LQTS infants, and significantly longer than that during night-time sleep in controls.
\end{abstract}

Conclusions: A combination of the longest QTc and autonomic imbalance during night-time sleep in early infancy may be responsible for development of life-threatening arrhythmia in LQTS infants. Critical cases should be included in future studies.

Key Words: Autonomic function; QT interval; Sleep; Sudden infant death

C ongenital long QT syndrome (LQTS) is a genetic disorder characterized by delayed repolarization and a long QT interval on 12-lead electrocardiography (ECG). The hallmark of LQTS is syncope or sudden death due to torsade de pointes. ${ }^{1-3}$ Sudden infant death syndrome (SIDS) is one of the major causes of death in infancy, with the highest prevalence between 2 and 4 months of age, ${ }^{46}$ and up to $83 \%$ of SIDS deaths occur during night-time sleep. ${ }^{78}$ SIDS is multi-factorial in origin, ${ }^{46}$ but prolongation of the QT interval in the first week of life is strongly associated with SIDS, ${ }^{9}$ and on genetic analysis approximately $10 \%$ of SIDS victims carry functionally significant mutations in LQTS genes. ${ }^{10,11}$

The autonomic nervous system plays an important role in the modulation of cardiac electrophysiology and arrhythmogenesis. ${ }^{12}$ Autonomic function matures in infancy, especially in early infancy. ${ }^{13,14}$ An abnormality in cardiac sympathetic innervation or in its development is thought to be associated with a prolonged QT interval. ${ }^{15}$ SIDS is most prevalent during early infancy, and heart rate variability (HRV), one of the most promising quantitative markers of autonomic activity, ${ }^{16}$ has been assessed in pre-term and term infants, and in infants who later died of SIDS, during sleep in early infancy. ${ }^{13,14,17-19}$ In these studies, the association between autonomic function and QT interval was also examined, ${ }^{18,19}$ but many studies were performed only during daytime sleep ${ }^{13,14,18}$ or night-time sleep..$^{17,19}$

The aims of the present study were therefore to assess the circadian change in autonomic function using HRV, and to clarify the differences in QT interval between nighttime sleep, daytime sleep, and daytime activity in LQTS infants before starting medication, and in age-matched control infants in early infancy. Autonomic function and QT interval were re-evaluated in late infancy in the same control infants to examine autonomic maturation from early to late infancy.

\section{Methods}

Participants

The participants consisted of 11 LQTS infants in early infancy (mean age, $11.8 \pm 7.5$ weeks) before $\beta$-blocker

Received January 15, 2018; revised manuscript received April 27, 2018; accepted May 7, 2018; released online June 27, 2018 Time for primary review: 17 days

Department of Pediatrics, National Hospital Organization Kagoshima Medical Center, Kagoshima (M.Y., Y.K.); Pediatric Cardiology, Ohori Children's Clinic, Fukuoka (H.U.); Department of the Cardiovascular System, Fukuoka Children's Hospital, Fukuoka (Y.I.); Center for Epidemiologic Research in Asia, Shiga University of Medical Science, Ohtsu (S.O.); and Epidemiology and Biostatistics, Kagawa Nutrition University, Sakado (H.O.), Japan

Mailing address: Masao Yoshinaga, MD, PhD, Department of Pediatrics, National Hospital Organization Kagoshima Medical Center, 8-1 Shiroyama-cho, Kagoshima 892-0853, Japan. E-mail: m-yoshi@biscuit.ocn.ne.jp

ISSN-1346-9843 All rights are reserved to the Japanese Circulation Society. For permissions, please e-mail: cj@j-circ.or.jp 
treatment and 11 age-matched control infants (Table 1). The control infants were re-evaluated in late infancy (mean age, 39.6 \pm 5.6 weeks). The LQTS infants were not assessed in late infancy, because all LQTS infants were taking $\beta$-blockers and the dose per day differed between them (Table 2). ${ }^{20}$ The study was approved by the Ethics Committee of the National Hospital Organization Kagoshima Medical Center.

\section{Diagnosis of LQTS in Infancy}

LQTS was diagnosed when infants had a corrected QT interval by Bazett's formula (QTc) $\geq 470 \mathrm{~ms}$ on resting ECG, and prolonged QTc was sustained during follow-up at 2 or 3 weeks. ${ }^{20}$ Infants with QTc $\geq 500 \mathrm{~ms}$ on Holter ECG were treated with medication to prevent LQTS-related symptoms during infancy, and they were also diagnosed with LQTS (Table 2). No infants had ventricular tachycardias such as torsade de pointes, syncope, or cardiac arrest.

\section{Genetic Testing}

Genetic testing was performed after obtaining written informed consent. In the first genetic testing, screening for LQT1 (KCNQ1), -2 (KCNH2), -3 (SCN5A), -5 (KCNE1), -6 (KCNE2), and -7 (KCNJ2) was performed using polymerase chain reaction and direct DNA sequencing. ${ }^{21}$ When no pathogenic mutations were identified, in the first study, genes related to LQTS and catecholaminergic polymorphic ventricular tachycardia were retrospectively screened using a targeted gene sequencing method with the HaloPlex Target Enrichment System (Agilent Technology, San Diego, CA, USA) and the MiSeq system (Illumina, San Diego, CA, USA). Detected variants were confirmed using Sanger's method. ${ }^{22}$

\section{HRV}

Two-channel 24-h Holter ECG monitoring was performed in all infants. HRV was analyzed on a Holter analysis system (SCM-8000, Ver 54-11, Fukuda Denshi, Tokyo, Japan). After manual checks of the QRS configuration, an $\mathrm{R}$ wave was inserted at the midpoint of the long period, when non-normal $\mathrm{R}$ wave was detected. The number of non-normal $\mathrm{R}$ waves was trivial in the present study. In LQTS infants, control infants in early infancy, and control infants in late infancy, the median of the non-normal $\mathrm{R}$ waves was 0.5 beats/day (range, $0-54$ beats/day), 0.5 beats/day (range, $0-27$ beats/day), and 0.5 beats/day (range, 0-9 beats/day), respectively. The power spectral density was computed as low-frequency (LF; 0.04-0.15 Hz)

\begin{tabular}{|lccc|}
\hline \multicolumn{4}{|c|}{ Table 1. Participant Characteristics } \\
LQTS & Control & P-value \\
No. participants & 11 & 11 & \\
Sex (M/F) & $6 / 5$ & $5 / 6$ & 0.67 \\
Gestational age & $39.1 \pm 1.0$ & $39.1 \pm 1.2$ & 0.56 \\
(weeks) & & & \\
Birth weight (g) & $2,991 \pm 496$ & $2,974 \pm 355$ & 0.90 \\
Early infancy & & & \\
$\quad$ Age (weeks) & $11.8 \pm 7.5$ & $11.6 \pm 3.4$ & 0.52 \\
$\quad$ Weight (g) & $5,414 \pm 1,332$ & $5,623 \pm 729$ & 0.85 \\
Late infancy & & & \\
$\quad$ Age (weeks) & - & $39.6 \pm 5.6$ & \\
Weight (g) & - & $7,915 \pm 1,092$ & \\
\hline
\end{tabular}

Data given as mean \pm SD. LQTS, long QT syndrome.

\begin{tabular}{|c|c|c|c|c|c|c|c|c|c|c|c|c|}
\hline \multirow{2}{*}{ ID no } & \multirow{2}{*}{ Sex } & \multicolumn{2}{|c|}{ First ECG† } & \multicolumn{2}{|c|}{$\underset{(\text { rest })^{\ddagger}}{\operatorname{Maximum}}$ QTc } & \multicolumn{2}{|c|}{$\begin{array}{c}\text { Maximum QTc } \\
(\text { Holter) } \\
\end{array}$} & \multirow{2}{*}{$\begin{array}{l}\text { Diagnostic } \\
\text { events }\end{array}$} & \multirow{2}{*}{ Genes } & \multirow{2}{*}{ Mutations } & \multicolumn{2}{|c|}{ Medication } \\
\hline & & $\begin{array}{c}\text { Age } \\
\text { (weeks) }\end{array}$ & QTC & $\begin{array}{c}\text { Age } \\
\text { (weeks) }\end{array}$ & QTC & $\begin{array}{c}\text { Age } \\
\text { (weeks) }\end{array}$ & QTC & & & & $\begin{array}{l}\text { Propranolol } \\
\text { (mg/kg/day) }\end{array}$ & $\begin{array}{c}\text { Mexiletine } \\
\text { (mg/kg/day) }\end{array}$ \\
\hline 1 & $\mathrm{~F}$ & 12.4 & 0.520 & 12.4 & 0.520 & 12.4 & 0.496 & $\begin{array}{l}\text { Family } \\
\text { (mother) }\end{array}$ & $K C N Q 1$ & $\begin{array}{l}\text { c. } 502 G>A, \\
\text { p.G168R }\end{array}$ & 1.0 & $(-)$ \\
\hline 2 & M & 4.4 & 0.458 & 9.1 & 0.472 & 7.3 & 0.527 & $\begin{array}{c}\text { ECG } \\
\text { screening" }\end{array}$ & & (Not identified) & 0.7 & 3.6 \\
\hline 3 & M & 5.3 & 0.483 & 5.3 & 0.483 & 5.3 & 0.534 & $\begin{array}{c}\text { ECG } \\
\text { screening? }\end{array}$ & $\mathrm{KCNH} 2$ & $\begin{array}{c}\text { c.3065delT, } \\
\text { p.L1022Pfs }+35 X\end{array}$ & 0.9 & 3.0 \\
\hline 4 & $\mathrm{~F}$ & 3.9 & 0.485 & 15.9 & 0.491 & 47.9 & 0.501 & $\begin{array}{l}\text { Family } \\
\text { (father) }\end{array}$ & $K C N Q 1$ & $\begin{array}{c}\text { c.563delG, } \\
\text { p.R190Gfs+47X }\end{array}$ & 1.6 & $(-)$ \\
\hline 5 & M & 7.6 & 0.470 & 7.6 & 0.470 & 7.6 & 0.504 & $\begin{array}{l}\text { Family } \\
\text { (mother) }\end{array}$ & $\mathrm{KCNH} 2$ & c.65T>A, p.F22Y & 0.3 & 6.0 \\
\hline 6 & $M$ & 23.6 & 0.432 & 30.9 & 0.462 & 23.6 & 0.536 & By chance & & (Not identified) & 1.1 & 2.3 \\
\hline 7 & $F$ & 4.1 & 0.451 & 15.0 & 0.512 & 37.1 & 0.520 & $\begin{array}{l}\text { Family } \\
\text { (father) }\end{array}$ & $K C N Q 1$ & $\begin{array}{l}\text { c. } 1663 \mathrm{C}>\mathrm{T} \\
\text { p.R555C }\end{array}$ & 1.8 & $(-)$ \\
\hline 8 & $\mathrm{~F}$ & 4.1 & 0.469 & 7.3 & 0.498 & 7.3 & 0.510 & $\begin{array}{c}\text { ECG } \\
\text { screening }{ }^{\dagger \dagger}\end{array}$ & & (Not identified) & 1.9 & 4.9 \\
\hline 9 & $\mathrm{~F}$ & 4.6 & 0.450 & 10.9 & 0.510 & 13.4 & 0.514 & $\begin{array}{c}\text { ECG } \\
\text { screening }{ }^{\dagger \dagger}\end{array}$ & & (Not identified) & 1.6 & $(-)$ \\
\hline 10 & $M$ & 4.6 & 0.456 & 25.6 & 0.489 & 28.4 & 0.504 & $\begin{array}{c}\text { ECG } \\
\text { screening }{ }^{\dagger \dagger}\end{array}$ & & (Not identified) & 1.9 & $(-)$ \\
\hline 11 & $M$ & 8.0 & 0.486 & 10.9 & 0.488 & 8.0 & 0.518 & $\begin{array}{l}\text { Family } \\
\text { (mother) }\end{array}$ & KCNH2 & $\begin{array}{c}\text { c. } 503 \mathrm{C}>\mathrm{T}, \mathrm{p} . \\
\text { P168L }\end{array}$ & 2.1 & $(-)$ \\
\hline
\end{tabular}

${ }^{\dagger}$ At first visit to hospital or at ECG screening; ₹on resting ECG at outpatient clinic; §on Holter ECG. "ECG screening of 1-month-old infants to identify prolonged QT interval between 2010 and 2011;20 +tECG screening of 1-month-old infants to identify prolonged QT interval between 2014 and 2016 (Yoshinaga M; unpublished data, 2018). ECG, electrocardiography; LQTS, long QT syndrome; QTc, Bazett's corrected QT. 


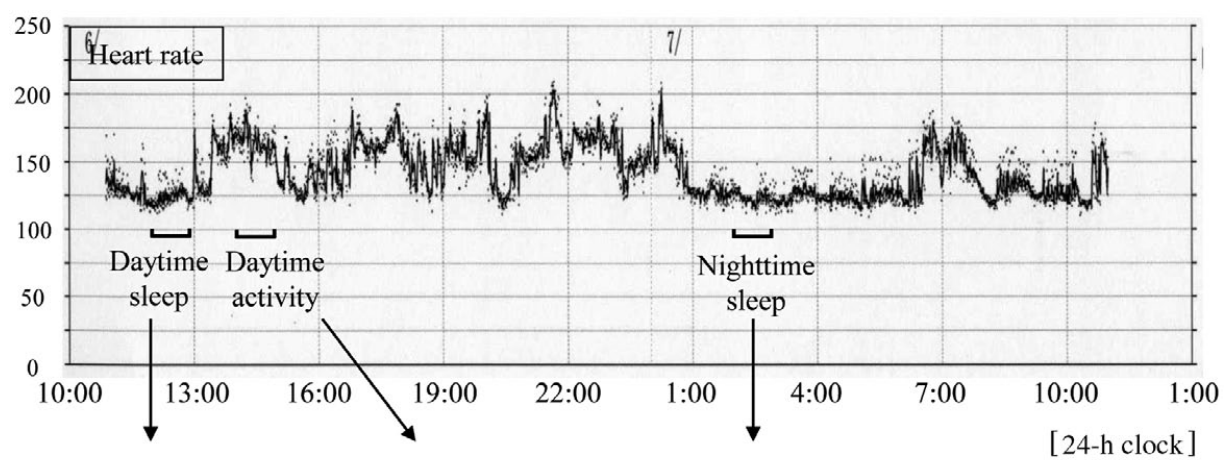

$\begin{array}{ccc}\text { Three ECGs at } & \text { Three ECGs at } & \text { Three ECGs at } \\ \text { maximum, average, \& } & \text { maximum, average, \& } & \text { maximum, average, \& } \\ \text { minimum heart rates } & \text { minimum heart rates } & \text { minimum heart rates }\end{array}$

Figure 1. Selection of representative hour for night-time sleep, daytime sleep, and for daytime activity, in a representative case (long QT syndrome patient 8; 7 weeks of age). ECG, electrocardiogram.

and high-frequency (HF; $0.15-0.40 \mathrm{~Hz}$ ) components in 60-min segments with a 1024-point fast Fourier transform algorithm and a frequency resolution of $0.008 \mathrm{~Hz}$. The logarithm of these component values was used. The $\mathrm{Ln}(\mathrm{HF})$ component and the $\{\mathrm{Ln}(\mathrm{LF}) / \mathrm{Ln}(\mathrm{HF})\}$ ratio were used as indices of parasympathetic activity ${ }^{23,24}$ and the sympathovagal balance of the heart, respectively. ${ }^{23,24}$ To investigate the circadian variability of $\mathrm{HRV}$, spectral data variables were averaged for each hour throughout the day.

\section{QT/RR Interval Measurement}

QT/RR intervals were measured at three selected periods: during night-time sleep; daytime sleep; and during daytime activity. In the present study, night-time and daytime were defined as 23:00-06:00 hours and as 07:00-18:00 hours, respectively. An hour during which the total beats per hour was lowest during the night-time and daytime was chosen for the night-time sleep and daytime sleep, respectively, and an hour during which the total beats per hour was highest during daytime was chosen for the daytime activity period (Figure 1).

Three ECG at maximum, average, and minimum heart rates were printed out at the representative hour during night-time sleep, daytime sleep, and daytime activity. For each ECG, three consecutive QT/RR intervals were manually measured using the tangent method by one of the authors (M.Y.). Bazett's formula was used to calculate QTc in the present study, because this correction had a more significant association with autonomic function than Fridericia's formula in each period (data not shown).

\section{QTc and Autonomic Activity}

To determine the association between QTc and autonomic activity, a 5-min HRV segment was obtained with a 256point fast Fourier transform algorithm, setting the QT/RR measurement beats at the midpoint of each 5-min segment.

\section{Statistical Analysis}

Differences in the means were examined using MannWhitney U-test or Wilcoxon signed-ranks test. Differences in QTc and heart rate between night-time sleep, daytime sleep, and daytime activity were analyzed using Friedman's
ANOVA and the Dunn-Bonferroni tests. Spearman's rank test was used to evaluate the correlation coefficients. Statistical analysis was performed using IBM SPSS Statistics 23 (IBM Japan, Tokyo, Japan). A two-tailed $\mathrm{P}<0.05$ was considered statistically significant.

\section{Results}

\section{Participant Characteristics}

Gestational age, birth weight, and weight in early infancy were not different between the LQTS and control infants (Table 1). Mutations were identified in 6 of 11 LQTS infants (KCNQ1 in 3 and $K C N H 2$ in 3; Table 2). The mutation in LQTS infant 5 was finally determined on targeted gene screening. Diagnostic events were identified in family studies in five infants and ECG screening programs in five, and by chance in one. ECG screening to identify prolonged QT interval in 1-month-old infants was performed from 2010 to $2011^{20}$ and from 2014 to 2016 .

\section{Circadian Changes in Autonomic Activity in Infancy}

LQTS infants had a significantly lower Ln(HF) component at 23:00 hours, 02:00 hours, 03:00 hours, and 06:00 hours than age-matched control infants (Figure 2A). Conversely, LQTS infants had a higher $\mathrm{Ln}(\mathrm{LF}) / \mathrm{Ln}(\mathrm{HR})$ ratio than control infants during night-time at 00:00 hours, 02:00 hours, and at 04:00 hours (Figure 2B). The power of the $\mathrm{Ln}(\mathrm{HF})$ component in early infancy in both LQTS infants and control infants, however, was significantly lowered from 23:00 to 03:00 hours, from 05:00 to 07:00 hours, and at 11:00, 12:00, and 15:00 hours compared with that in late infancy in control infants. Conversely, the $\mathrm{Ln}(\mathrm{LF}) / \mathrm{Ln}(\mathrm{HF})$ ratio in early infancy was significantly higher than in late infancy at 23:00 hours, 02:00 hours, and 03:00 hours; from 05:00 to 08:00 hours; and at 11:00, 12:00, and 15:00 hours.

With respect to the autonomic activity according to LQTS genotype, there was no difference in $\mathrm{Ln}(\mathrm{HF})$ components or in $\{\mathrm{Ln}(\mathrm{LF}) / \mathrm{Ln}(\mathrm{HF})\}$ ratio at each hour between infants with the LQT1 and LQT2 genotypes.

\section{QTC}

Mean QTc in LQTS infants was longer at the maximum 

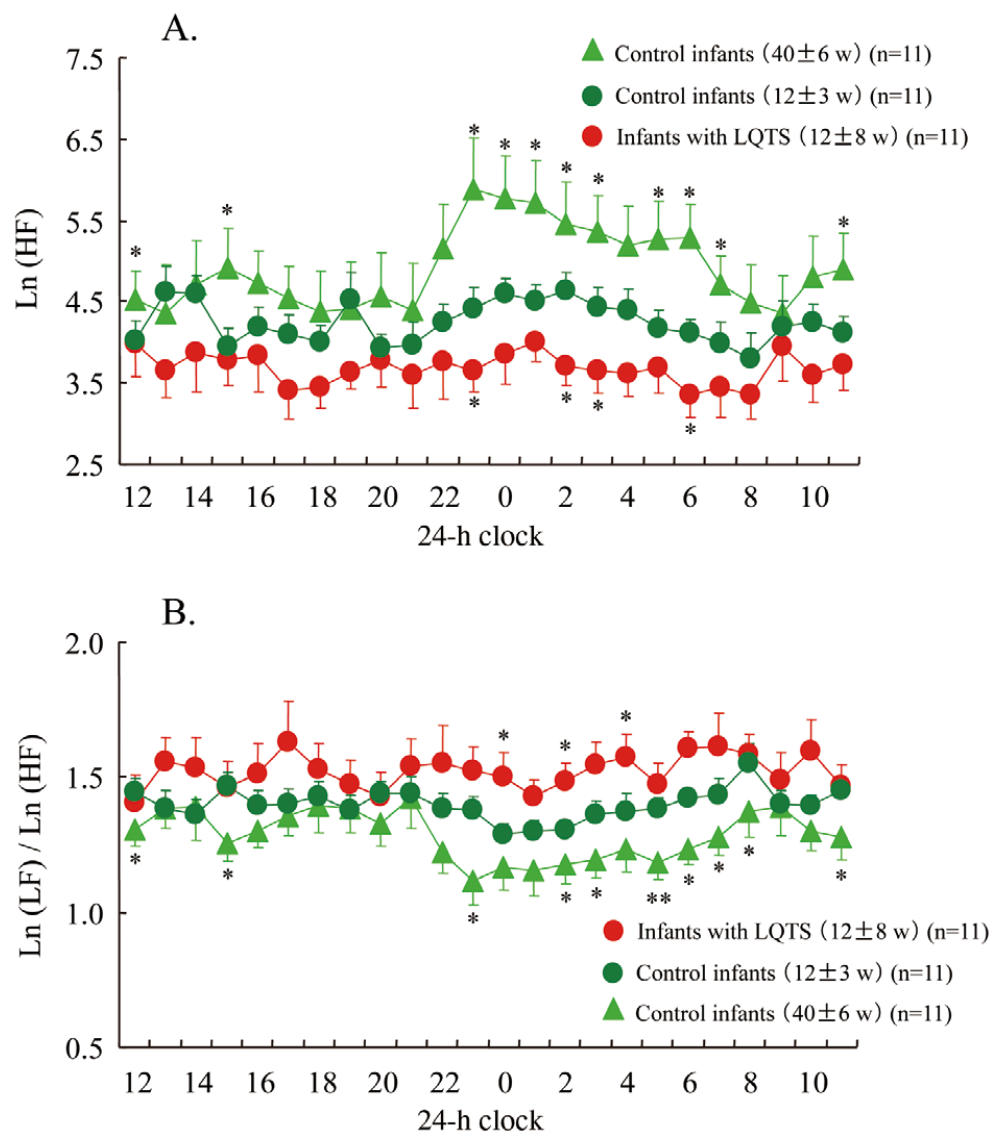

Figure 2. Circadian automatic changes in the natural logarithms of the high frequency component ( $\mathrm{Ln}(\mathrm{HF})$ ) and of the low frequency component $(\mathrm{Ln}(\mathrm{LF}))$ in long QT syndrome (LQTS) infants and control infants. Data given as mean and SEM. ${ }^{\star} \mathrm{P}<0.05 ;{ }^{\star \star} \mathrm{P}<0.01$.

\begin{tabular}{|c|c|c|c|c|c|c|c|}
\hline & \multicolumn{3}{|c|}{ QTc (ms) } & \multicolumn{4}{|c|}{ P-value } \\
\hline & $\begin{array}{l}\text { Maximum HR } \\
\text { (A) }\end{array}$ & $\begin{array}{l}\text { Average HR } \\
\text { (B) }\end{array}$ & $\begin{array}{l}\text { Minimum HR } \\
\text { (C) }\end{array}$ & $\begin{array}{l}\text { Friedman } \\
\text { test }\end{array}$ & A vs. $B$ & A vs. $C$ & B vs. C \\
\hline \multicolumn{8}{|l|}{ LQTS infants } \\
\hline Night-time sleep & $490 \pm 20$ & $467 \pm 22$ & $431 \pm 29$ & $<0.001$ & 0.17 & $<0.001$ & 0.03 \\
\hline Daytime sleep & $477 \pm 21$ & $459 \pm 25$ & $440 \pm 24$ & 0.002 & 0.17 & 0.001 & 0.33 \\
\hline Daytime activity & $458 \pm 18$ & $447 \pm 19$ & $449 \pm 23$ & $0.09^{\dagger}$ & $\mathrm{NS}^{\dagger}$ & $\mathrm{NS}^{+}$ & $\mathrm{NS}^{\dagger}$ \\
\hline \multicolumn{8}{|c|}{ Control infants in early infancy } \\
\hline Night-time sleep & $437 \pm 11$ & $415 \pm 19$ & $370 \pm 19$ & $<0.001$ & 0.17 & $<0.001$ & 0.03 \\
\hline Daytime sleep & $435 \pm 9$ & $414 \pm 14$ & $380 \pm 17$ & $<0.001$ & 0.60 & $<0.001$ & 0.01 \\
\hline Daytime activity & $409 \pm 14$ & $410 \pm 22$ & $381 \pm 19$ & 0.003 & 1.00 & 0.004 & 0.03 \\
\hline \multicolumn{8}{|c|}{ Control infants in late infancy } \\
\hline Night-time sleep & $433 \pm 23$ & $397 \pm 15$ & $359 \pm 24$ & $<0.001$ & 0.17 & $<0.001$ & 0.03 \\
\hline Daytime sleep & $423 \pm 16$ & $399 \pm 23$ & $364 \pm 27$ & $<0.001$ & 0.10 & $<0.001$ & 0.10 \\
\hline Daytime activity & $411 \pm 24$ & $395 \pm 22$ & $373 \pm 19$ & 0.001 & 0.10 & 0.001 & 0.41 \\
\hline
\end{tabular}

Data given as mean \pm SD. †Multiple comparison test not performed. NS, not significant (Friedman's ANOVA). Other abbreviations as in Table 2.

heart rate than at the average and at the minimum heart rates during night-time and daytime sleep (Table 3). In control infants, mean QTc at maximum heart rate was longer than at minimum heart rate during night-time and daytime sleep and daytime activity. Heart rate during these three periods is listed in Table S1.

At maximum heart rate, QTc in LQTS infants during night-time sleep was significantly longer than that in controls during night-time sleep (Figure 3A). In LQTS infants, QTc during night-time sleep was significantly longer than that during daytime sleep and daytime activity (Figure 3A). In early infancy in controls, QTc during sleep was longer than that during daytime activity. In late infancy in controls, a significant difference was still present between 

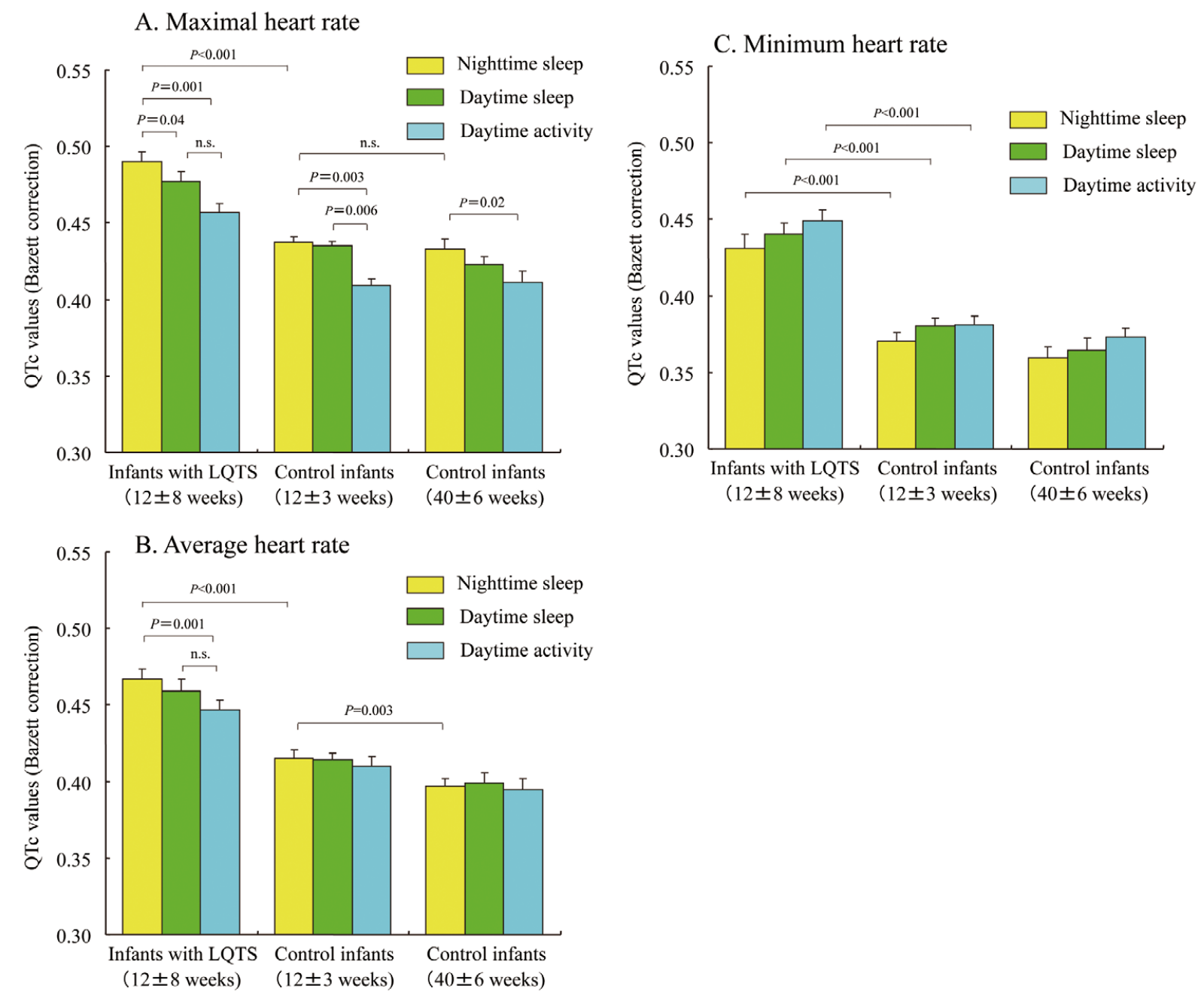

Figure 3. Bazett's corrected QT (QTc) at (A) maximum, (B) average, and (C) minimum heart rate in infants according to long QT syndrome (LQTS) status, time of day, and stage of infancy. Data given as mean and SEM.

night-time sleep and daytime activity.

At average heart rate in LQTS infants, QTc during night-time sleep was longer than that during daytime activity (Figure 3B). No significant difference was seen in QTc between the three periods in controls. At the minimum heart rate, no significant difference was seen between the three periods in both LQTS infants and in control infants (Figure 3C).

With respect to QTc according to LQTS genotype, QTc at average heart rate during midnight sleep in LQT2 infants was significantly longer than that in LQT1 infants ( $497 \pm 19$ vs. $477 \pm 17 \mathrm{~ms}$, respectively; $\mathrm{P}=0.0495$ ).

\section{QTc and Autonomic Activity}

There was no significant association between QTc and autonomic activity in early infancy when assessed separately in LQTS or in control infants (Table S2). The associations were then re-assessed after combining the data of the LQTS infants and control infants in early infancy. During night-time sleep, QTc had a significantly negative association with $\mathrm{Ln}(\mathrm{HF})$ at the maximum, average, and minimum heart rate, and a significantly positive association with sympathovagal imbalance at the minimum heart rate (Table 4; Figure 4).

\section{Discussion}

LQTS infants had significantly lower parasympathetic activity and higher sympathovagal balance during several night-time hours than control infants in early infancy, but autonomic function in both LQTS infants and control infants in early infancy showed significantly decreased parasympathetic and increased sympathovagal conditions compared with that in late infancy in control infants. Under the conditions of this autonomic dysfunction, LQTS infants had significantly longer QTc at maximum heart rate during night-time sleep than during daytime sleep or daytime activity in early infancy.

In studies of infantile autonomic activity, both term and preterm control infants had increased parasympathetic activity from early infancy to late infancy during daytime sleep ${ }^{13,14}$ or night-time sleep. ${ }^{17}$ In the present study of the 
Table 4. QTC and HRV in Early Infancy vs. LQTS Status

\begin{tabular}{|c|c|c|c|c|c|c|}
\hline & \multicolumn{2}{|c|}{ Night-time sleep } & \multicolumn{2}{|c|}{ Daytime sleep } & \multicolumn{2}{|c|}{ Daytime activity } \\
\hline & Ln(HF) & Ln(LF)/Ln(HF) & Ln(HF) & Ln(LF)/Ln(HF) & Ln(HF) & $\operatorname{Ln}(\mathrm{LF}) / \operatorname{Ln}(\mathrm{HF})$ \\
\hline \multicolumn{7}{|c|}{ QTc at maximum HR } \\
\hline Coefficient & -0.447 & 0.379 & -0.018 & 0.294 & -0.100 & -0.089 \\
\hline P-value & 0.04 & 0.08 & 0.94 & 0.19 & 0.66 & 0.70 \\
\hline \multicolumn{7}{|c|}{ QTc at average HR } \\
\hline Coefficient & -0.451 & 0.377 & -0.390 & 0.470 & -0.130 & -0.023 \\
\hline $\mathrm{P}$-value & 0.04 & 0.08 & 0.07 & 0.03 & 0.56 & 0.92 \\
\hline \multicolumn{7}{|c|}{ QTc at minimum HR } \\
\hline Coefficient & -0.586 & 0.512 & -0.272 & 0.346 & -0.142 & -0.034 \\
\hline$P$-value & 0.004 & 0.02 & 0.22 & 0.12 & 0.53 & 0.88 \\
\hline
\end{tabular}

$\mathrm{HF}$, high frequency; HR, heart rate; HRV, heart rate variability; LF, low frequency. Other abbreviations as in Table 2.

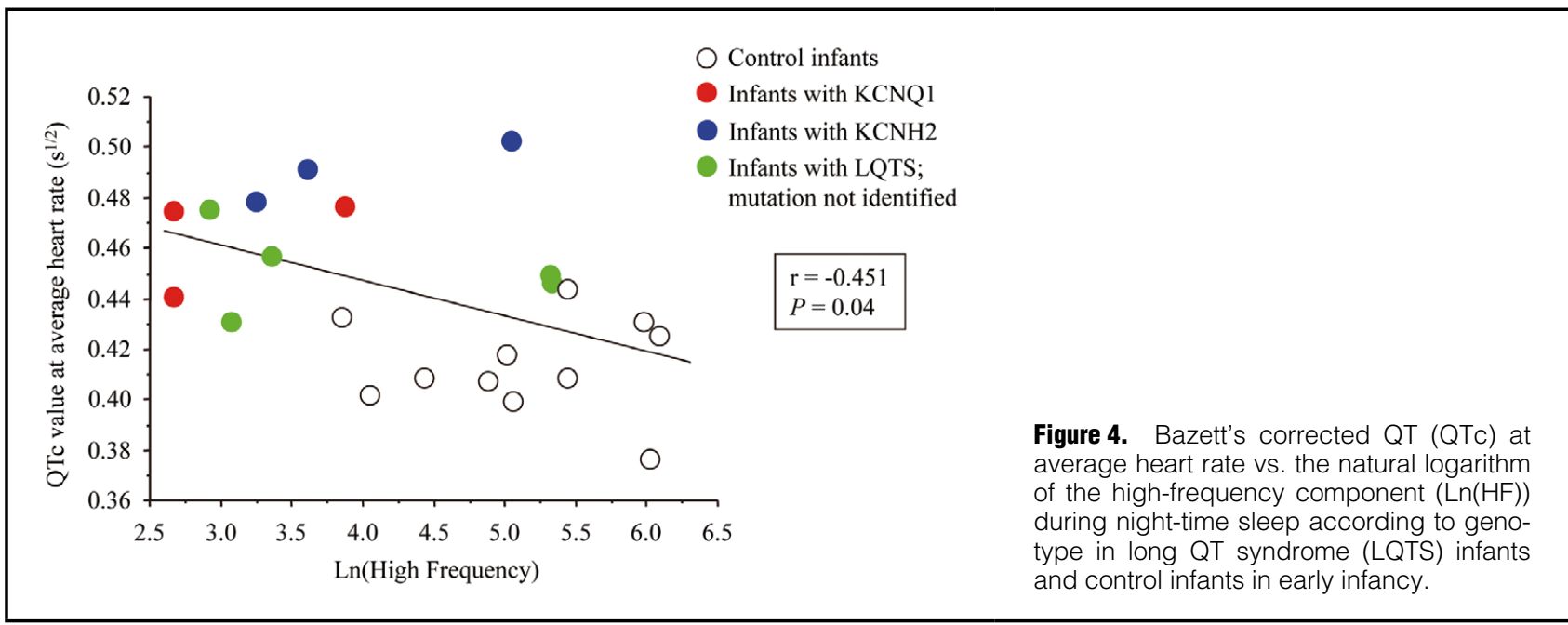

circadian changes in autonomic activity, $\mathrm{Ln}(\mathrm{HF})$ power was augmented and $\mathrm{Ln}(\mathrm{LF}) / \mathrm{Ln}(\mathrm{HF})$ ratio was decreased throughout the day, and especially during night-time sleep, from early to late infancy in control infants. This indicates that low parasympathetic activity and a high sympathovagal balance are present during night-time sleep in early infancy. The $\mathrm{Ln}(\mathrm{HF})$ power during night-time sleep was negatively associated with QTc, when the data of LQTS and control infants were combined. Considering that sympathetic stimulation precipitates ventricular tachyarrhythmias and sudden cardiac death in patients with LQTS, ${ }^{\mathbf{1 2}}$ the presence of autonomic immaturity during night-time sleep in early infancy is thought to be a high risk factor for life-threatening arrhythmias in LQTS infants.

In the $1970 \mathrm{~s}$, Schwartz proposed a hypothesis that an abnormality in cardiac sympathetic innervation or in its development was associated with QT prolongation and was associated with the development of SIDS. ${ }^{15}$ This hypothesis prompted many investigators to measure the QT interval during sleep in healthy controls and in patients with disease conditions. Additionally, during rapid eye movement (REM) sleep, conditions of intermittent bursts of sympathetic activity are present on a background of powerful bursts of parasympathetic activity. ${ }^{25-27}$ Many studies involving adults supported these findings. The QT interval during night-time sleep is longer than that during the daytime or in the awake state, ${ }^{28-30}$ and QTc during REM sleep was longer than that during non-REM sleep, if present. ${ }^{31,32}$

In the pediatric field, however, the effect of sleep on QT interval was contradictory. Haddad et al measured computer-assisted QT interval in daytime sleep $2-3 \mathrm{~h}$ after midmorning feed, and reported that QTc in REM sleep was shorter than that during non-REM sleep in control infants, ${ }^{33,34}$ and in infants who had an aborted SIDS episode in early infancy. ${ }^{34}$ Montague et al determined computer-assisted QTc at five random times throughout the 24-h Holter monitoring period and reported that maximum QTc at these five time points was significantly shorter in infants at risk for SIDS than in age- and sexmatched control infants. ${ }^{35}$ Conversely, Franco et al reported that QTc in infants who later died of SIDS was significantly longer than that in age-matched control infants in the REM, non-REM sleep, and total sleep period, ${ }^{19}$ but that QTc was not different between REM and non-REM sleep in these future SIDS victims. ${ }^{19}$ There are some possible explanations for these discrepancies. Computer-assisted averaged ECG configurations, used in some studies, ${ }^{33-35}$ may not be applicable for infants and children because sinus arrhythmia is frequent and beat-to-beat QT/RR intervals are largely changeable in these age groups. In the study that used manual QT measurement, one set of three 
consecutive beats was chosen for REM and non-REM analysis; ${ }^{19}$ this might result in loss of QTc during the intermittent burst of sympathetic activity (at maximum heart rate) and at the powerful burst of parasympathetic activity (at minimum heart rate).

In the present study, therefore, three sets of QT/RR intervals were selected and manually measured at the maximum, average, and minimum heart rates during night-time sleep, daytime sleep and in daytime activity. QTc at the maximum heart rate in night-time sleep may correspond to the condition of intermittent bursts of sympathetic activity on a background of parasympathetic activity. At the maximum heart rate, LQTS infants had a significantly longer QTc during night-time sleep than during daytime sleep or daytime activity. In early infancy in the controls, QTc during night-time and daytime sleep was significantly longer than that during daytime activity. This indicates that night-time sleep is associated with a risk for longer QTc in early infancy, especially in LQTS infants.

No infants with $S C N 5 A$ mutations were included in the present study. In a study of postmortem genetic screening in victims of SIDS, the most prevalent gene was SCN5 . $^{10,11}$ Arnestad et al reported on 19 SIDS victims with pathogenic mutations associated with LQTS in Norway: five, five, and 13 patients had $K C N Q 1, K C N H 2$, and SCN5A mutations, respectively. ${ }^{10}$ Otagiri et al reported on four SIDS victims in Japan, consisting of one with $K C N Q 1$, one with $K C N H 2$, two with $S C N 5 A$, and one with digenic $K C N H 2$ and $S C N 5 A$ mutation. ${ }^{11}$ Conversely, Horigome et al reported on 58 infants with congenital LQTS in Japan diagnosed in the fetal, neonatal, and infantile periods, including 11 with $K C N Q 1,11$ with $K C N H 2$, and 6 with $S C N 5 A$ mutations. ${ }^{36}$ They also reported that one patient each from these three genotype groups developed aborted cardiac arrest. This suggests that the most prevalent genotypes of congenital LQTS diagnosed in the infantile period are $K C N Q 1$ and/or $\mathrm{KCNH} 2$ when we combine the SIDS victims and the patients diagnosed in the infantile period. No data that can explain the absence of patients with SCN5A mutations were available in the present study; this might have occurred by chance because of the small number of patients included. Infants with SCN5A mutations, however, should be included in a future study.

This study also had some other limitations. First, the number of LQTS infants was small and the present study did not include any infants who later died of SIDS or who were at risk for SIDS, although several previous studies have. ${ }^{19,33,35}$ This means that the present study was not able to investigate the direct association between LQTS and SIDS. To determine accurate autonomic activity in LQTS infants, it is essential to assess the function without the effect of $\beta$-blocker. It is impossible to examine 24-Holter ECG in critical LQTS infants without medication. In the present study, we were able to perform 24-Holter ECG partly because ECG screening programs were present at 1-month medical check-up; accumulation of data, however, including critical cases before treatment, is warranted. Second, we did not determine the sleep stage, especially the REM stage. Further studies including the sleep stages are needed. Third, diagnostic criteria for QT prolongation in Holter ECG data are currently unavailable. With regard to computer-assisted QT measurements on Holter ECG in adults, an early study in 1996 showed that mean QTc in 21 adults was $443 \pm 15 \mathrm{~ms}$, and that 6 of these 21 adults had maximum QTc $\geq 500 \mathrm{~ms} ;{ }^{28}$ in a recent study in 2016 , however, computer-assisted QTc was $400 \pm 16 \mathrm{~ms}$ in $101 \mathrm{men}$ and $416 \pm 16 \mathrm{~ms}$ in 99 women, ${ }^{37}$ suggesting that QTc $\geq 500 \mathrm{~ms}$ in control adults is a rarity. ${ }^{37} \mathrm{In}$ the present study, maximum QTc during night-time sleep in control infants was $456 \mathrm{~ms}$. We then used QTc $>500 \mathrm{~ms}$ for QT prolongation in Holter ECG data, which, on resting ECG, is a high risk factor in patients with LQTS. ${ }^{38}$ Finally, in future studies, LQTS infants should be classified by genotype to improve the risk stratification for targeted management according to genotype or mutation type. ${ }^{39}$

\section{Conclusions}

A combination of two major risk factors may be responsible for development of life-threatening arrhythmia in LQTS infants: longest QTc and autonomic imbalance; and undeveloped parasympathetic activity and accentuated sympathovagal balance, during night-time sleep in early infancy. To prevent sudden infant death from QT prolongation, screening of infants with prolonged QT interval in early infancy is essential because $\beta$-blocker therapy is known to shorten QT interval and to decrease LQTS-related symptoms, although strategies to screen infants with QT prolongation are still controversial.40,41

\section{Disclosures}

The authors declare no conflicts of interest.

\section{Grants}

This work was partly supported by a Health and Labour Sciences Research Grant from the Ministry of Health, Labour and Welfare of Japan (H22-032, H26-002, and H29-055), and by a research grant (KAKENHI) from the Ministry of Education, Culture, Sports, Science and Technology of Japan (15K09689).

\section{References}

1. Schwartz PJ, Moss AJ, Vincent GM, Crampton RS. Diagnostic criteria for the long QT syndrome: An update. Circulation 1993; 88: $782-784$.

2. Schwartz PJ, Crotti L, Insolia R. Long-QT syndrome: From genetics to management. Circ Arrhythm Electrophysiol 2012; 5: 868-877.

3. Vink AS, Clur SB, Geskus RB, Blank AC, De Kezel CC, Yoshinaga M, et al. Effect of age and sex on the QTc interval in children and adolescents with type 1 and 2 long-QT syndrome. Circ Arrhythm Electrophysiol 2017; 10: e004645.

4. Guntheroth WG, Spiers PS. The triple risk hypotheses in sudden infant death syndrome. Pediatrics 2002; 110: e64.

5. Task Force on Sudden Infant Death Syndrome, Moon RY. SIDS and other sleep-related infant deaths: Expansion of recommendations for a safe infant sleeping environment. Pediatrics 2011; 128: 1030-1039.

6. Fleming PJ, Blair PS, Pease A. Sudden unexpected death in infancy: Aetiology, pathophysiology, epidemiology and prevention in 2015. Arch Dis Child 2015; 100: 984-988.

7. Williams SM, Mitchell EA, Taylor BJ. Are risk factors for sudden infant death syndrome different at night? Arch Dis Child 2002; 87: 274-278.

8. Blair PS, Platt MW, Smith IJ, Fleming PJ; SESDI SUDI Research Group. Sudden infant death syndrome and the time of death: Factors associated with night-time and day-time deaths. Int J Epidemiol 2006; 35: 1563-1569.

9. Schwartz PJ, Stramba-Badiale M, Segantini A, Austoni P, Bosi $\mathrm{G}$, Giorgetti R, et al. Prolongation of the QT interval and the sudden infant death syndrome. $N$ Engl J Med 1998; 338: 17091714 .

10. Arnestad M, Crotti L, Rognum TO, Insolia R, Pedrazzini M, Ferrandi $C$, et al. Prevalence of long-QT syndrome gene variants in sudden infant death syndrome. Circulation 2007; 115: $361-367$.

11. Otagiri T, Kijima K, Osawa M, Ishii K, Makita N, Matoba R, et al. Cardiac ion channel gene mutations in sudden infant death 
syndrome. Pediatr Res 2008; 64: 482-487.

12. Shen MJ, Zipes DP. Role of the autonomic nervous system in modulating cardiac arrhythmias. Circ Res 2014; 114: 1004-1021.

13. Yiallourou SR, Sands SA, Walker AM, Horne RS. Maturation of heart rate and blood pressure variability during sleep in term-born infants. Sleep 2012; 35: 177-186.

14. Fyfe KL, Yiallourou SR, Wong FY, Odoi A, Walker AM, Horne RS. The effect of gestational age at birth on post-term maturation of heart rate variability. Sleep 2015; 38: 1635-1644.

15. Schwartz PJ. Cardiac sympathetic innervation and the sudden infant death syndrome: A possible pathogenetic link. Am J Med 1976; 60: $167-172$.

16. Heart rate variability. Standards of measurement, physiological interpretation, and clinical use: Task Force of the European Society of Cardiology and the North American Society of Pacing and Electrophysiology. Eur Heart J 1996; 17: 354-381.

17. Massin MM, Withofs N, Maeyns K, Ravet F, Gérard P. Normal ranges for the variability in heart rate in young infants while sleeping. Cardiol Young 2001; 11: 619-625.

18. Ariagno RL, Mirmiran M, Adams MM, Saporito AG, Dubin AM, Baldwin RB. Effect of position on sleep, heart rate variability, and QT interval in preterm infants at 1 and 3 months' corrected age. Pediatrics 2003; 111: 622-625.

19. Franco P, Groswasser J, Scaillet S, Lanquart JP, Benatar A, Sastre JP, et al. QT interval prolongation in future SIDS victims: A polysomnographic study. Sleep 2008; 31: 1691-1699.

20. Yoshinaga M, Ushinohama H, Sato S, Tauchi N, Horigome H, Takahashi H, et al. Electrocardiographic screening of 1-month-old infants for identifying prolonged QT intervals. Circ Arrhythm Electrophysiol 2013; 6: 932-938.

21. Yoshinaga M, Kucho Y, Nishibatake M, Ogata H, Nomura Y. Probability of diagnosing long QT syndrome in children and adolescents according to the criteria of the HRS/EHRA/APHRS expert consensus statement. Eur Heart J 2016; 37: 2490-2497.

22. Sanger F, Nicklen S, Coulson AR. DNA sequencing with chain-terminating inhibitors. Proc Natl Acad Sci USA 1977; 74: $5463-5467$.

23. Billman GE. Heart rate variability: A historical perspective. Front Physiol 2011; 2: 86.

24. Yanagi S, Yoshinaga M, Horigome H, Tanaka Y, Husazaki N, Matusoka Y, et al. Heart rate variability and ambulatory blood pressure monitoring in young patients with hypertrophic cardiomyopathy. Circ J 2004; 68: 757-762.

25. Somers VK, Dyken ME, Mark AL, Abboud FM. Sympatheticnerve activity during sleep in normal subjects. $N$ Engl $J$ Med 1993; 328: 303-307.

26. Verrier RL, Muller JE, Hobson JA. Sleep, dreams, and sudden death: The case for sleep as an autonomic stress test for the heart. Cardiovasc Res 1996; 31: 181-211.

27. Garcia-Touchard A, Somers VK, Kara T, Nykodym J, Shamsuzzaman A, Lanfranchi P, et al. Ventricular ectopy during REM sleep: Implications for nocturnal sudden cardiac death. Nat Clin Pract Cardiovasc Med 2007; 4: 284-288.

28. Molnar J, Zhang F, Weiss J, Ehlert FA, Rosenthal JE. Diurnal pattern of QTc interval: How long is prolonged? Possible relation to circadian triggers of cardiovascular events. $\mathrm{J} \mathrm{Am} \mathrm{Coll} \mathrm{Cardiol}$ 1996; 27: 76-83.
29. Browne KF, Prystowsky E, Heger JJ, Chilson DA, Zipes DP. Prolongation of the Q-T interval in man during sleep. Am $J$ Cardiol 1983; 52: 55-59.

30. Murakawa Y, Inoue H, Nozaki A, Sugimoto T. Role of sympathovagal interaction in diurnal variation of QT interval. Am J Cardiol 1992; 69: 339-343.

31. Lanfranchi PA, Shamsuzzaman AS, Ackerman MJ, Kara T, Jurak P, Wolk R, et al. Sex-selective QT prolongation during rapid eye movement sleep. Circulation 2002; 106: 1488-1492.

32. Lanfranchi PA, Ackerman MJ, Kara T, Shamsuzzaman AS, Wolk R, Jurak P, et al. Gene-specific paradoxical QT responses during rapid eye movement sleep in women with congenital long QT syndrome. Heart Rhythm 2010; 7: 1067-1074.

33. Haddad GG, Krongrad E, Epstein RA, Epstein MA, Law HS, Katz JB, et al. Effect of sleep state on the QT interval in normal infants. Pediatr Res 1979; 13: 139-141.

34. Haddad GG, Epstein MA, Epstein RA, Mazza NM, Mellins RB, Krongrad E. The QT interval in aborted sudden infant death syndrome infants. Pediatr Res 1979; 13: 136-138.

35. Montague TJ, Finley JP, Mukelabai K, Black SA, Rigby SM, Spencer CA, et al. Cardiac rhythm, rate and ventricular repolarization properties in infants at risk for sudden infant death syndrome: Comparison with age- and sex-matched control infants. Am J Cardiol 1984; 54: 301-307.

36. Horigome $\mathrm{H}$, Nagashima $\mathrm{M}$, Sumitomo N, Yoshinaga $\mathrm{M}$, Ushinohama $\mathrm{H}$, Iwamoto $\mathrm{M}$, et al. Clinical characteristics and genetic background of congenital long QT syndrome diagnosed in fetal, neonatal and infantile life: A nation-wide questionnaire survey in Japan. Circ Arrhythm Electrophysiol 2010; 3: 10-17.

37. Page A, Aktas MK, Soyata T, Zareba W, Couderc JP. "QT clock" to improve detection of QT prolongation in long QT syndrome patients. Heart Rhythm 2016; 13: 190-198.

38. Priori SG, Schwartz PJ, Napolitano C, Bloise R, Ronchetti E, Grillo M, et al. Risk stratification in the long-QT syndrome. $N$ Engl J Med 2003; 348: 1866-1874.

39. Porta A, Girardengo G, Bari V, George AL Jr, Brink PA, Goosen A, et al. Autonomic control of heart rate and QT interval variability influences arrhythmic risk in long QT syndrome type 1. J Am Coll Cardiol 2015; 65: 367-374.

40. Saul JP, Schwartz PJ, Ackerman MJ, Triedman JK. Rationale and objectives for ECG screening in infancy. Heart Rhythm 2014; 11: 2316-2321.

41. Skinner JR, Van Hare GF. Routine ECG screening in infancy and early childhood should not be performed. Heart Rhythm 2014; 11: 2322-2327.

\section{Supplementary Files}

\section{Supplementary File 1}

Table S1. HR vs. time of day, sleep and LQTS status

Table S2. QTc and HRV correlations in early infancy vs. LQTS status

Please find supplementary file(s);

http://dx.doi.org/10.1253/circj.CJ-18-0048 